\title{
Ribosomal S6 Kinase Cooperates with Casein Kinase 2 to Modulate the Drosophila Circadian Molecular Oscillator
}

\author{
Bikem Akten, ${ }^{1 *}$ Michelle M. Tangredi, ${ }^{1 *}$ Eike Jauch, ${ }^{2}$ Mary A. Roberts, ${ }^{1}$ Fanny Ng, ${ }^{1}$ Thomas Raabe, ${ }^{2}$ and F. Rob Jackson ${ }^{1}$ \\ ${ }^{1}$ Department of Neuroscience, Tufts Center for Neuroscience Research, Sackler School of Graduate Biomedical Sciences, Tufts University School of \\ Medicine, Boston, Massachusetts 02111, and 2University of Wuerzburg, Institut für Medizinische Strahlenkunde und Zellforschung, 97078 Wuerzburg, \\ Germany
}

There is a universal requirement for post-translational regulatory mechanisms in circadian clock systems. Previous work in Drosophila has identified several kinases, phosphatases, and an E3 ligase that are critical for determining the nuclear translocation and/or stability of clock proteins. The present study evaluated the function of p90 ribosomal S6 kinase (RSK) in the Drosophila circadian system. In mammals, RSK1 is a light- and clock-regulated kinase known to be activated by the mitogen-activated protein kinase pathway, but there is no direct evidence that it functions as a component of the circadian system. Here, we show that Drosophila S6KII RNA displays rhythms in abundance, indicative of circadian control. Importantly, an S6KII null mutant exhibits a short-period circadian phenotype that can be rescued by expression of the wild-type gene in clock neurons, indicating a role for S6KII in the molecular oscillator. Peak PER clock protein expression is elevated in the mutant, indicative of enhanced stability, whereas per mRNA level is decreased, consistent with enhanced feedback repression. Gene reporter assays show that decreased S6KII is associated with increased PER repression. Surprisingly, we demonstrate a physical interaction between S6KII and the casein kinase 2 regulatory subunit (CK2 $\beta$ ), suggesting a functional relationship between the two kinases. In support of such a relationship, there are genetic interactions between S6KII and CK2 mutations, in vivo, which indicate that $\mathrm{CK} 2$ activity is required for S6KII action. We propose that the two kinases cooperate within clock neurons to fine-tune circadian period, improving the precision of the clock mechanism.

Key words: circadian; post-transcriptional; p90 ribosomal S6 kinase; RSK1; casein kinase 2; MAP kinase

\section{Introduction}

Organisms possess endogenous clocks that enable them to synchronize to diurnal environmental cycles and anticipate time of day. In several model systems, it is known that the circadian molecular clock consists of transcriptional/translational autoregulatory feedback loops in which clock proteins translocate to the nucleus and regulate clock gene transcription (Reppert and Weaver, 2002; Dunlap and Loros, 2005; Hardin, 2005). In Drosophila, the molecular oscillator is composed of three feedback loops which are interlocked by virtue of the CLK control of per and tim gene transcription. The first loop results in rhythmic PERIOD (PER) and TIMELESS (TIM) clock protein production,

\footnotetext{
Received June 26, 2008; revised Dec. 8, 2008; accepted Dec. 9, 2008.

This work was supported by National Institutes of Health (NIH) Grant R01 NS45817 to F.R.J., National Science Foundation Fellowship DGE 0238731 to M.M.T., a grant from the Deutsche Forschungsgemeinschaft (SFB581/B14) to T.R., and a center grant to the Tufts Center for Neuroscience Research (NIH P30 NS047243; Pl; F.R.J.). We thank Dr. Alenka Lovy-Wheeler of the Tufts Imaging Facility for help with confocal microscopy, Dr. Lax lyer and Chris Parkin of the Tufts Center for Neuroscience Research Computational Genomics Core for help with statistics, Michael Rosbash for help with cell-based per repression assays, anonymous reviewers for their comments, and members of the Jackson lab for help with fly collections.

*B.A. and M.M.T. contributed equally to this work.

Correspondence should be addressed to F. Rob Jackson, Department of Neuroscience, Tufts Center for Neuroscience Research, Sackler School of Graduate Biomedical Sciences, Tufts University School of Medicine, 136 Harrison Avenue, Boston, MA 02111. E-mail: rob.jackson@tufts.edu.

B. Akten's present address: Department of Neurology, Children's Hospital, 300 Longwood Avenue, Boston, MA 02115.

DOI:10.1523/JNEUROSCI.4034-08.2009

Copyright $\odot 2009$ Society for Neuroscience $\quad$ 0270-6474/09/290466-10\$15.00/0
}

the second generates rhythms in the CLOCK (CLK) transcription factor and the third (Clockwork Orange) modulates the expression of several clock genes known to be regulated by the CLK transcription factor by binding to the E-box regulatory element (Glossop et al., 1999; Cyran et al., 2003; Glossop et al., 2003; Yu et al., 2006; Kadener et al., 2007; Lim et al., 2007; Matsumoto et al., 2007; Richier et al., 2008). Certain recent results, however, indicate that the CLK cycle may be more important for output than oscillator function per se (Benito et al., 2007; Zheng and Sehgal, 2008).

In addition to a transcriptional requirement, circadian oscillators use post-transcriptional mechanisms to keep time (Young and Kay, 2001; Zheng and Sehgal, 2008). Prominent among such mechanisms in both flies and mammals is the phosphorylation of clock proteins, which controls their nuclear entry, stability and/or ability to repress clock gene transcription (Lee et al., 2001; Harms et al., 2004; Meng et al., 2008). In Drosophila, oscillations in PER/TIM accumulation, nuclear translocation and degradation are dependent on the activities of several protein kinases [casein kinase $1 \varepsilon(\mathrm{CK} 1 \varepsilon)$, casein kinase $2(\mathrm{CK} 2)$ and glycogen synthase kinase $3 \beta$ (GSK3 $\beta$ ) ], at least two protein phosphatases (PP2A and PP1) and an E3 ubiquitin ligase called SLIMB (Kloss et al., 1998; Price et al., 1998; Martinek et al., 2001; Grima et al., 2002; Ko et al., 2002; Akten et al., 2003; Sathyanarayanan et al., 2004; Fang et al., 2007). Remarkably, certain circadian oscillators can run for many cycles using only post-transcriptional mecha- 
nisms; a circadian rhythm in cyanobacterial KaiC autophosphorylation, for example, occurs for several cycles in vitro in the complete absence of transcriptional feedback (Tomita et al., 2005).

Given the ubiquitous requirement for post-translational mechanisms in circadian clock systems, it is of interest to identify additional kinases that might regulate oscillator function. In mammals, the p90 ribosomal S6 kinase (RSK1) is a light- and clock-regulated kinase known to be activated by the mitogenactivated protein kinase (MAPK) pathway (Butcher et al., 2004), although there is no direct evidence that it is required for oscillator function. Microarray-based studies have previously documented circadian changes in Drosophila S6KII (dRsk1) mRNA abundance, indicative of clock regulation (McDonald and Rosbash, 2001), and we have verified the microarray results in the current study using quantitative RT-PCR methods. Importantly, we show that S6KII null mutants display a short-period circadian rhythm phenotype that can be rescued by transgenic expression of the wild-type S6KII+ gene in clock neurons, demonstrating a role for the kinase in the molecular oscillator. Consistent with such a role, we report that PER abundance is altered in the S6KII mutant. Further, we show that Andante and Tik, mutations of the casein kinase 2 regulatory $(\mathrm{CK} 2 \beta)$ and catalytic (CK2 $\alpha)$ subunits, respectively, are epistatic to a S6KII mutation, indicating that CK2 $\beta$ activity is required for S6KII action. Based on the circadian period phenotypes of CK2 and S6KII mutants, we postulate that S6KII may negatively regulate CK2 activity. Our finding that S6KII can physically interact with CK $2 \beta$ supports this model. We propose that the two kinases cooperate to regulate clock gene expression and modulate circadian period.

\section{Materials and Methods}

Stock maintenance and genetic crosses. Drosophila cultures were reared at $25^{\circ} \mathrm{C}$ and $60 \%$ relative humidity in a $12 \mathrm{~h} \mathrm{light/dark} \mathrm{cycle} \mathrm{on} \mathrm{a} \mathrm{modified}$ standard medium containing wheat germ. For genetic crosses, flies were collected using $\mathrm{CO}_{2}$ anesthesia.

Standard genetic crosses and visible markers [yellow $(y)$, white $(w)$, dusky $(d y)$ and forked $(f)]$ were used to generate a recombinant X chromosome carrying both the $D f(1)$ ign $^{\Delta 58-1}$ (region 20C1) and Andante (region 10E3) mutations. Putative recombinants were then balanced against an attached $\mathrm{X}$ chromosome and backcrossed for three generations to the $w^{1118}$ strain to reduce background differences between genotypes. The absence of S6KII protein in the recombinant strains was confirmed by Western blot analysis using a rabbit anti-S6KII antibody (Putz et al., 2004).

Analysis of behavioral rhythmicity. Locomotor activity data from individual flies were collected using the Drosophila Activity Monitor system (Trikinetics). In most experiments, flies were entrained at $23^{\circ} \mathrm{C}$ to a $12 \mathrm{~h}$ light/dark cycle for $4 \mathrm{~d}$ and then transferred to constant darkness (DD) at the same temperature for $\sim 2$ weeks. Experiments using the Gal4 expression system were performed at $25^{\circ} \mathrm{C}$ to enhance Gal4 activity. To estimate period and visualize actograms, we used a MATLAB (MathWorks)based signal processing toolbox (Levine et al., 2002). Period was estimated from the third peak of the correlogram. Differences in circadian period were assessed for statistical significance using an unpaired $t$ test or an ANOVA with post hoc comparisons.

RNA preparation and real time quantitative PCR analysis. Flies were entrained in a $12 \mathrm{~h} \mathrm{light/dark}$ cycle for at least $4 \mathrm{~d}$, collected every $4 \mathrm{~h}$, and immediately frozen in liquid nitrogen. Lights were turned off and flies were collected every $4 \mathrm{~h}$ for the first day of constant darkness. Total RNA was isolated from adult heads using the TRIzol Reagent (Invitrogen) according to manufacturer's protocol. Sample RNA was treated with DNase I (Amplification Grade; Invitrogen) to eliminate genomic DNA contamination. First strand cDNA was synthesized from $1 \mu \mathrm{g}$ of RNA using Superscript II (Invitrogen). No-RT controls received water instead of transcriptase.

Real-time quantitative PCR was performed using SYBR Green PCR
Master Mix (Applied Biosystems) on a Stratagene Mx3000p real-time thermal cycler. Reactions contained $10 \mathrm{~nm}$ S6KII gene-specific primers, $10 \mathrm{~nm} r p 49$ gene-specific primers or $30 \mathrm{~nm}$ period gene-specific primers. The primers were: S6KII forward, 5'-CAGTGTGCCGGCCAAAGAAC3'; S6KII reverse, 5'-GCAGCCAGTCGTGCTCAAGTATTCG-3'; Rp49 forward, 5'-GCCCAAGATCGTGAAGAAGC-3'; Rp49 reverse, 5' CGACGCACTCTGTTGTCG-3'; Period forward, 5'-TAGTAGCCACACCCGCAGT-3'; Period reverse, 5'-GCAATGGAAGGGGGAGTTAG-3' ${ }^{\prime}$ RT-PCR conditions were $10 \mathrm{~min}$ at $95^{\circ} \mathrm{C}$, followed by 40 cycles of $30 \mathrm{~s}$ at $95^{\circ} \mathrm{C}$ and $22 \mathrm{~s}$ at $55^{\circ} \mathrm{C}$. Relative mRNA abundances were calculated from cycle threshold $(\mathrm{Ct})$ values and normalized to $r p 49$ abundance. Mean \pm SEM was calculated from three independent experiments.

PER feedback repression assays. To examine the involvement of S6KII in PER-mediated repression, we performed assays of E-box-luc transgene activity in S2 cells. S2 cell transfections, RNA interference (RNAi) and luciferase activity assays were performed as described by Nawathean and Rosbash (2004). Briefly, double-stranded RNA was transcribed from vectors described in Nawathean and Rosbash (2004) and used for knockdown of S6KII and CK2 $\alpha$. S2 cells were incubated with $15 \mathrm{ng} / \mathrm{ml} \mathrm{CK2} \alpha-$ or $30 \mathrm{ng} / \mathrm{ml}$ S6KII-specific dsRNAs $48 \mathrm{~h}$ before DNA transfections. Using Cellfectin (Invitrogen), $5 \mathrm{ng}$ of $p A c c l k, 15 \mathrm{ng}$ of $p A c$ per, $25 \mathrm{ng}$ of $p$ Copia Renilla luciferase and $25 \mathrm{ng}$ of an artificial E-box reporter construct (3×69 firefly luciferase) were transfected into S2 cells. All plasmid constructs were obtained from M. Rosbash (Brandeis University, Waltham, MA). Luciferase activity was measured using a Packard Top Count luminometer with the Dual-Luciferase Reporter Assay System (Promega). Firefly luciferase activity driven by the $3 \times 69$ E-box reporter construct was normalized to constitutively expressed Renilla luciferase as an internal control for transfection efficiency. Luciferase values were normalized between experiments, for visualization, by expressing values as a percentage of the no RNAi control. To evaluate statistical significance, values from each experiment were normalized using the formula: Xnorm $=$ $[\mathrm{X}$-mean $(\mathrm{X})] / \mathrm{SD}(\mathrm{X})$ to represent the number of SDs from the mean.

Western analyses and immunostaining methods. Fly heads were collected every $4 \mathrm{~h}$ and homogenized in 3 volumes of Head Extraction Buffer (50 mм KCl, 10 mм HEPES, 5 mм Tris-HCl, 10\% glycerol, 2 mм EDTA, $1 \%$ Triton X-100) with $1 \mathrm{~mm}$ DTT, 0.4\% NP40, $0.5 \mathrm{~mm}$ PMSF, $10 \mathrm{~mm}$ pNPP and a 1:100 dilution of Halt protease inhibitor mixture (Pierce). Extract buffer for pS6KII blots also contained a 1:10 dilution of PhosSTOP phosphatase inhibitor mixture (Roche). Standard immunoblotting techniques were used to examine protein abundance for S6KII, phosphorylated S6KII (pS6KII) and PERIOD. To generate gels for blotting, $75 \mu \mathrm{g}$ or $100 \mu \mathrm{g}$ of protein per time point were loaded for the detection of S6KII/pS6KII or PERIOD, respectively. The following antibodies were used: rabbit anti-S6KII, 1:500 (Putz et al., 2004), rabbit anti-RSK1-Ser363, 1:300 (Santa Cruz), rabbit anti-PERIOD, 1:1500 (Stanewsky et al., 1997), rat anti-N-cadherin, 1:300 (Developmental Studies Hybridoma Bank). Bands were visualized using the ECL Western Blotting detection system (Amersham Biosciences). Differences in S6KII protein abundance were assessed using KODAK 1D Image Analysis Software (Eastman Kodak Company) and analyzed with Welch's $t$ test. Differences in PER protein abundance were evaluated by blind scoring of relative immunoreactivity, on a scale of 1 to 5 , in three independent experiments.

Hand dissected whole mounts of the fly brain were stained with antibodies according to published procedures (Suh and Jackson, 2007). Rabbit anti-S6KII, rabbit anti-PER and mouse anti-PDF (Developmental Studies Hybridoma Bank) antisera were used at dilutions of 1:300, $1: 10,000$ and 1:50, respectively. The anti-S6KII antibody used for immunostaining was a gift of Dr. Jongkyeong Chung (Korea Advanced Institute of Science and Technology, Yusong, Taejon, Korea) (Kim et al., 2006). Brain images were acquired using a Leica TCS SP2 AOBS confocal microscope. Mean pixel intensities for the large and small LNvs (PDF cells) were measured from a $2 \mu \mathrm{m}$ section in the middle of the cell using the Leica LCS "Lite" software. Background intensity was subtracted from each measurement. The data from two independent experiments was analyzed by an unpaired $t$ test.

Protein expression and immunoprecipitation. The expression vectors for HA-tagged CK2 $\beta$ and 6xMyc tagged CK2 $\alpha$ are described in Jauch et 
al. (2006). The expression vector for CK2 $\beta^{\mathrm{C} 109,114 \mathrm{~S}}$ was generated by subcloning the open reading frame from an established pUAST construct (Jauch et al., 2002) into the pcDNA3-HA vector. The open reading frame of S6KII was amplified by linker PCR from a full-length cDNA clone (SD05277, Berkeley Drosophila Genome Project) and cloned into NotI and $\mathrm{XbaI}$ cut pcDNA3 vector $3^{\prime}$ to the $6 \mathrm{xMyc}$ epitope sequence. Human embryonic kidney (HEK) 293 cells were grown in DMEM (Invitrogen) containing $10 \%$ fetal calf serum (Invitrogen) at $37^{\circ} \mathrm{C}$ and $5 \% \mathrm{CO}_{2}$. Cells were transfected for transient protein expression using JetPEI transfection reagent (Poly + Transfections) following the manufacturers instructions and were then maintained for $48 \mathrm{~h}$ before lysis. Immunoprecipitations and Western blot analysis were performed as described (Jauch et al., 2006).

\section{Results}

\section{Rhythms in S6KII RNA abundance}

Multiple independent microarray-based studies have documented circadian changes in RNA abundance for several hundred mRNAs expressed in Drosophila head tissues (ClaridgeChang et al., 2001; McDonald and Rosbash, 2001; Ceriani et al., 2002; Ueda et al., 2002; Y. Lin et al., 2002). In one report, microarray analysis indicated that S6KII RNA cycled in abundance in both light/dark and constant dark conditions, with peak RNA abundance occurring in the late night/early morning (McDonald and Rosbash, 2001). Because S6KII cycling was observed in one such study but not in several others, we used quantitative realtime RT-PCR (Q-RT-PCR) with RNA samples from Drosophila head tissues to analyze the daily profile of S6KII RNA expression. Head tissue was used in these experiments, because the microarray-based study of McDonald and Rosbash had documented changes in S6KII abundance using such a preparation. In addition, the FlyAtlas database indicates that S6KII RNA is most abundant in the nervous system (Chintapalli et al., 2007). In accordance with the previous microarray result, we found that the level of S6KII RNA changes in a diurnal manner, with peak abundance occurring between Zeitgeber time (ZT) 22 and 1 (Fig. $1 A)$. As the S6KII transcriptional rhythm peaks near the beginning of subjective day, the gene might be regulated by the Pdp1/ Vrille transcription factors which have similar rhythmic profiles and compete for binding to a regulatory element within the Drosophila Clk gene (Cyran et al., 2003). Thus, it is of interest that consensus sequences for "strong binding" of Pdp1 (Lin et al., 1997) exist within the upstream region of the fly S6KII gene (data not shown).

We wished to determine whether the observed circadian change in S6KII RNA titer was translated into a rhythm of S6KII protein abundance, and thus we measured protein levels at six different times of the diurnal cycle. These studies indicated that S6KII protein abundance was relatively constant across the cycle in Drosophila head extracts (Fig. $1 B$ ). Thus, there may not be a rhythm in S6KII protein abundance, or perhaps more likely, there are differential and tissue-specific post-transcriptional regulatory mechanisms that mask rhythms of S6KII abundance in clock cells (i.e., S6KII may be rhythmic in clock cells but not other cell types). Similarly, an antibody against phospho-RSK1 (antiphospho-S363), that cross-reacts with fly S6KII (S498 of S6KII), did not detect rhythms in phosphorylation of the protein as assessed in Western blotting experiments with head or adult brain extracts (data not shown). The latter result, however, does not exclude rhythms of S6KII activation as there are many other conserved sites of phosphorylation on S6KII.

We attempted to localize S6KII in the fly brain and to determine if the protein exhibits rhythmic changes in abundance within clock cells using immunostaining methods with whole
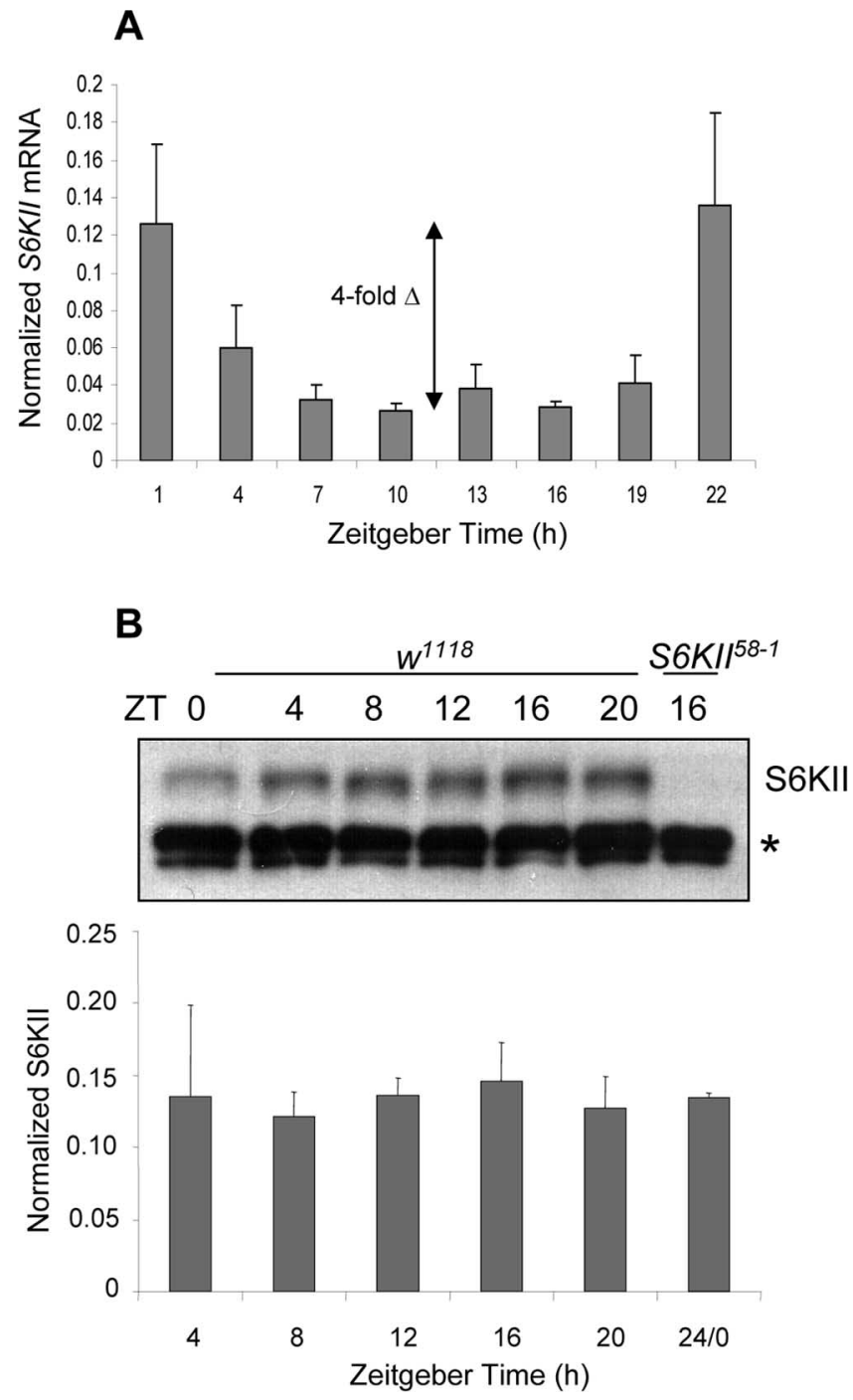

Figure 1. S6KII mRNA cycles in abundance in head tissue extracts, whereas rhythmicity is not observed for S6KII protein. $\boldsymbol{A}$, S6KII mRNA level at different times of day in $12 \mathrm{~h}$ light/dark. Relative S6KII mRNA level indicates the amount of S6KII message normalized to that of $r p 49$ (also see Materials and Methods). B, S6KII protein level at different times of a $12 \mathrm{~h}$ light/dark cycle. Histograms represent S6KII amount relative to the nonspecific band indicated by the asterisk. Note that the S6KII protein is absent in the $56 K I I^{58-1}$ null mutant. Illustrated results for $\boldsymbol{A}$ and $\boldsymbol{B}$ are averages \pm SEM from three different experiments.

mounts of the adult brain. However, neither anti-S6KII (Kim et al., 2006) nor anti-pS6KII antisera revealed obvious signals within the clock neuronal circuitry of wild-type flies. Thus, another antibody or different conditions might be required to determine the S6KII spatial expression pattern.

\section{S6KII mutants have altered behavioral periodicity}

To determine whether the elimination of S6KII activity disrupts circadian behavior, we analyzed locomotor activity rhythms in an S6KII null mutant $\left[D f(1)\right.$ ign $^{\Delta 58-1}$, hereafter called S6KII ign58-1 $]$. This mutant was generated by imprecise excision of a $P$ transposable element; it is known to be a viable protein null that exhibits deficits in learning and memory (Putz et al., 2004); hence, the name ignorant (ign). As shown in Figure 2 and Table 1, the S6KII ign58-1 null allele is associated with short circadian periods for the locomotor activity rhythm; average periods for this mutant were at least $1 \mathrm{~h}$ shorter than those observed in control flies.

Circadian period is known to be temperature compensated 

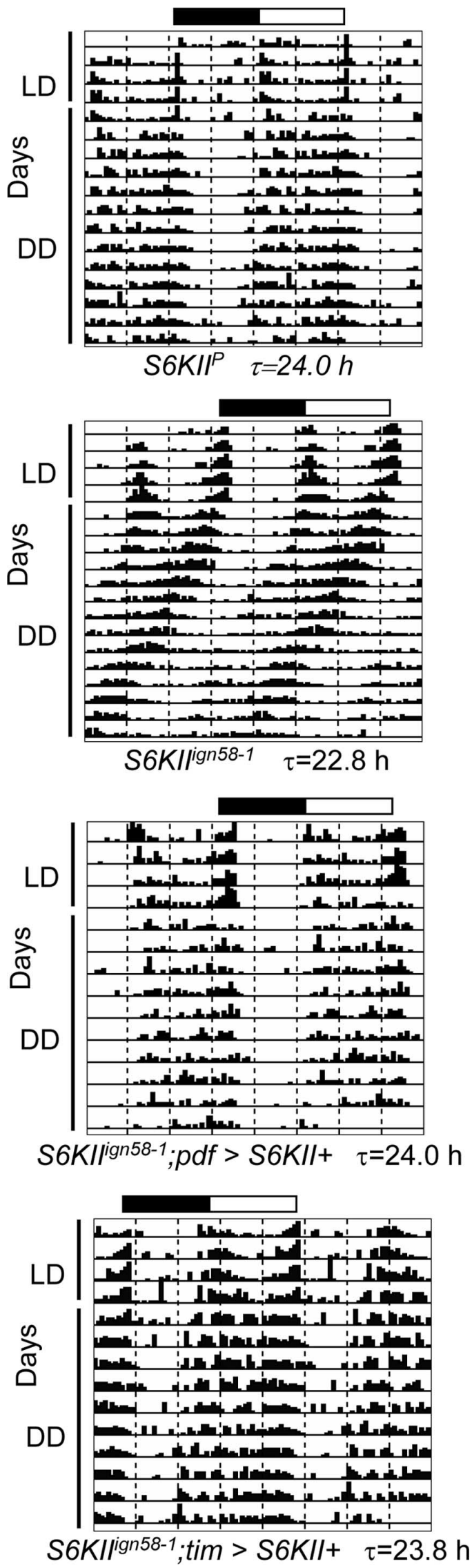

Figure 2. The S6KIIIn58-1 mutant has a short-period behavioral rhythm which can be rescued by expression of the wild-type gene in clock neurons. Panels show representative actograms from single flies of the indicated genotypes. Each genotype was examined in at least
Table 1. Period estimates and sample sizes for $56 \mathrm{KII}$ mutants and other genotypes

\begin{tabular}{|c|c|c|}
\hline Genotype $^{a}$ & $t(\mathrm{~h} \pm \mathrm{SEM})$ & $n$ \\
\hline S6KIII ${ }^{i g n 58-1} / \mathrm{Y}$ & $23.0 \pm 0.3^{b}$ & 72 \\
\hline S6KIII ${ }^{\text {ignP }} / \mathrm{Y}$ (control) & $24.2 \pm 0.2$ & 56 \\
\hline $\mathrm{w}^{1118}$ (control) & $24.0 \pm 0.2$ & 41 \\
\hline S6KIIIgn58-1 $/ \mathrm{Y}, 20^{\circ} \mathrm{C}$ & $23.0 \pm 0.07^{b}$ & 81 \\
\hline $\mathrm{w}^{1118}$ (control), $20^{\circ} \mathrm{C}$ & $24.2 \pm 0.05$ & 112 \\
\hline S6KIIIn58-1 $/ \mathrm{Y}, 25^{\circ} \mathrm{C}$ & $23.3 \pm 0.06^{b}$ & 51 \\
\hline $\mathrm{w}^{1118}$ (control), $25^{\circ} \mathrm{C}$ & $24.3 \pm 0.05$ & 59 \\
\hline $\mathrm{S} 6 \mathrm{KIII}{ }^{\mathrm{ign} 58-1} / \mathrm{Y}, 29^{\circ} \mathrm{C}$ & $23.1 \pm 0.06^{b}$ & 87 \\
\hline $\mathrm{w}^{1118}$ (control), $29^{\circ} \mathrm{C}$ & $23.6 \pm 0.03$ & 97 \\
\hline S6KIIIn58-1 $/ \mathrm{Y} ;\left.\mathrm{S} 6 \mathrm{KII}\right|^{5-5} /+$ & $23.7 \pm 0.04^{c}$ & 67 \\
\hline $\mathrm{w}^{1118} / \mathrm{Y} ;\left.S 6 \mathrm{KII}\right|^{5-5} /+$ (control) & $23.7 \pm 0.05$ & 30 \\
\hline $\mathrm{w}^{1118}$ (control) & $23.6 \pm 0.06$ & 49 \\
\hline S6KII ${ }^{\text {ign58-1}} / \mathrm{Y}, 20^{\circ} \mathrm{C}$ & $22.9 \pm 0.07$ & 71 \\
\hline S6KIII ${ }^{i g n 58-1} / \mathrm{Y}$, tim-UAS-Gal4/+, $20^{\circ} \mathrm{C}$ & $23.0 \pm 0.07$ & 70 \\
\hline S6KIIIgn58-1 $/ \mathrm{Y}, \mathrm{UAS}-\mathrm{S} 6 \mathrm{KII} /+, 20^{\circ} \mathrm{C}$ & $23.2 \pm 0.06$ & 73 \\
\hline S6KIII ${ }^{\text {ign58-1 }} / \mathrm{Y} ;$ tim-UAS-Gal4/+;UAS-S6KIII,$+ 20^{\circ} \mathrm{C}$ & $23.7 \pm 0.04^{e}$ & 90 \\
\hline S6KIII ${ }^{\text {ign58-1 }} /$ Y;tim-Gal4/+;UAS-S6KII/+ & $23.6 \pm 0.05^{e}$ & 78 \\
\hline S6KIIIgn58-1/Y;+/+;UAS-S6KII/+ & $23.1 \pm 0.06$ & 52 \\
\hline S6KIII ${ }^{\text {ign58-1 }} /$ Y;pdf-Gal4/+;UAS-S6KII/+ & $23.8 \pm 0.04^{d}$ & 90 \\
\hline $\begin{array}{l}\mathrm{w}^{1118} / \mathrm{Y} \text {;tim-UAS-Gal4/+;UAS-S6KIII/+ (S6KII + } \\
\text { overexpression) }\end{array}$ & $24.0 \pm 0.08^{c}$ & 18 \\
\hline $\mathrm{w}^{1118}$ (overexpression control) & $24.1 \pm 0.04$ & 58 \\
\hline Andante/Y (control) & $25.1 \pm 0.08$ & 40 \\
\hline Andante, S6KIII ${ }^{\text {ignP }} / \mathrm{Y}$ (control) & $24.9 \pm 0.07$ & 30 \\
\hline Andante, S6KIII ${ }^{\text {ign } 58-1} / \mathrm{Y}$ & $25.0 \pm 0.1^{c}$ & 37 \\
\hline S6KIII ${ }^{\text {ignP }} / \mathrm{Y}_{\text {;iTik/ }}+$ (control) & $26.3 \pm 0.06$ & 42 \\
\hline S6KIII ${ }^{\text {ign} 58-1} / Y_{; j} ; \mathrm{Tik} /+$ & $26.1 \pm 0.05^{c}$ & 39 \\
\hline
\end{tabular}

Bold indicates short-period phenotypes.

${ }^{a}$ Activity was monitored at $23^{\circ} \mathrm{C}$ in all experiments except those reported with different temperatures. ${ }^{b}$ Different from respective controls, $p<0.001$.

Not significantly different from control(s).

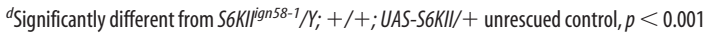

eSignificantly different from both unrescued controls, $p<0.001$.

although it varies across a physiological range of temperatures. We systematically compared circadian period in the S6KII ${ }^{\text {ign }} 58-1$ mutant and wild type at $20^{\circ} \mathrm{C}, 25^{\circ} \mathrm{C}$ and $29^{\circ} \mathrm{C}$. Period was reasonably compensated in the mutant with the difference between genotypes being most apparent at $20^{\circ} \mathrm{C}$ (a temperature at which there was an approximate $1.2 \mathrm{~h}$ difference between the two genotypes) (Table 1). However, whereas circadian period became shorter in an S6KII+ control strain $\left(w^{1118}\right)$ with increasing temperature, consistent with published results (Konopka et al., 1989), it became longer in the mutant and therefore the difference between genotypes was less pronounced at $29^{\circ} \mathrm{C}$. We do not understand the significance of the slightly anomalous compensation of the mutant.

In the mammalian suprachiasmatic nuclei (SCN), phosphorylation of RSK1 can be regulated by the clock (via the clock control of MAPK signaling; (Obrietan and Impey, 1998) or by light (Butcher et al., 2004). Light induces both phosphorylation of RSK1 and its translocation to the nuclei of SCN cells (Butcher et al., 2004). Interestingly, the light-induced phosphorylation of

$\leftarrow$

three independent experiments. The black and white rectangles above the actograms represent the light/dark cycle to which flies were entrained; placement of the light/dark bars in the first and last panels differs from the others simply because the activity data were saved at different times of day in those experiments. Flies were entrained to $12 \mathrm{~h}$ light/dark (LD) for $3-4 \mathrm{~d}$ and then maintained in constant darkness (DD) for a period of at least $10 \mathrm{~d}$. $56 \mathrm{KII}^{\text {ign }}{ }^{\mathrm{g}-1}$ is a null allele

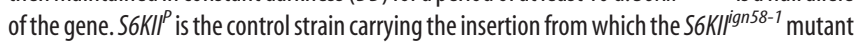
was derived. tim and $p d f$ indicate the tim-Gal4 and pdf-Gal4 drivers, respectively; S6KII+ represents a UAS-S6KII+ transgene. Results for other control genotypes are shown in Table 1. 
RSK1 is restricted to the night portion of the cycle, similar to what has been documented for MAPK pathway activation (Obrietan and Impey, 1998), indicative of a role in light resetting of the clock. Thus, we were interested in whether fly S6KII might have a similar role in light resetting. To address this question, we examined light-induced phase delays and advances in S6KII ign58-1 and control flies. In two different experiments, we found no evidence of diminished light responses in the mutant. In one experiment, the average advances were $1.9 \pm 0.3 \mathrm{~h}(n=32$ flies $)$, $1.3 \pm 0.31 \mathrm{~h}(n=27)$ and $1.7 \pm 0.26 \mathrm{~h}$ $(n=20)$ for S6KII ign58-1 , the control $P$ strain and $w^{1118}$ flies, respectively, whereas average delays were $-3.8 \pm 0.26 \mathrm{~h}(n=$ $42),-2.8 \pm 0.36 \mathrm{~h}(n=27)$ and $-3.4 \pm$ $0.24 \mathrm{~h}(n=30)$ for the three types of flies, respectively. This set of light-resetting experiments was repeated with similar results (data not shown). Thus, light resetting appears to be normal in S6KII ${ }^{\text {ign58-1 }}$ flies, although there might be an effect of the mutation at lower light fluences (our experiments used 1 min pulses of white fluorescent light at a fluence of $\sim 8 \mu \mathrm{mol} \mathrm{m}^{-2} \mathrm{~s}^{-1}$ ).

\section{S6KII function is required within clock cells for normal behavioral rhythmicity}

To show that the short-period phenotype of S6KII ${ }^{i g n 58-1}$ flies is due to a lesion in the S6KII gene, we generated flies carrying one of three different wild-type S6KII+ genomic transgene insertions (Putz et al., 2004). Table 1 shows that one of these insertions $\left(S 6 \mathrm{KII}^{5-5}\right)$ rescued the circadian period phenotype; the other two insertions did not rescue behavior (data not shown). In S6KII ${ }^{\text {ign58-1 }}$; S6KII ${ }^{5-5}$ flies, S6KII protein amount is comparable with that of the wild type, whereas protein amounts are less in other transgenic lines that failed to show evidence of rescue (Putz et al., 2004)(data not shown). Finally, we note that increasing S6KII+ gene dosage in a wild-type background (in $w^{1118} / \mathrm{Y}$; S6KII ${ }^{5-5} /+$ flies) had no effect on circadian period (Table 1), demonstrating that S6KII activity is not rate limiting for the modulation of period.

We wished to determine where S6KII function is required within clock neurons for the regulation of locomotor activity rhythms. The neural pattern of S6KII localization is unknown, because the existing S6KII antibody has not worked for immunostaining of wild-type brains. Thus, to address this question, we attempted rescue of the null mutant by driving expression of a UAS-S6KII + transgene (Rintelen et al., 2001) with different celltype-specific Gal4 transgenes. Expression of S6KII in TIMcontaining clock cells (using tim-Gal4 or tim-UAS-Gal4) or PDF clock cells (using pdf-Gal4) restored near normal circadian periods to mutants (Fig. 2, Table 1). These results demonstrate that S6KII expression within PDF clock cells is sufficient for normal behavioral rhythmicity. Similar to the results with a genomic transgene (see above), increased S6KII + dosage in a wild-type background, $w^{1118}$; tim-UAS-Gal4; UAS-S6KII flies, had no effect on circadian period (Table 1).
S6KIIIgn58-1
ZT1
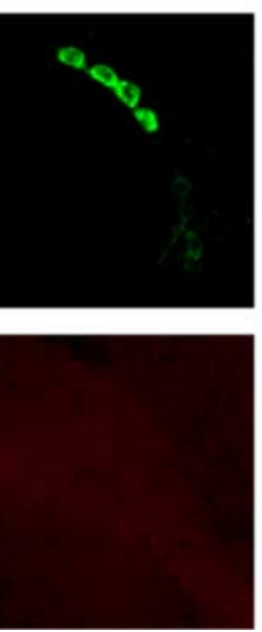

pdf $>$ UAS-S6KII+ ZT1
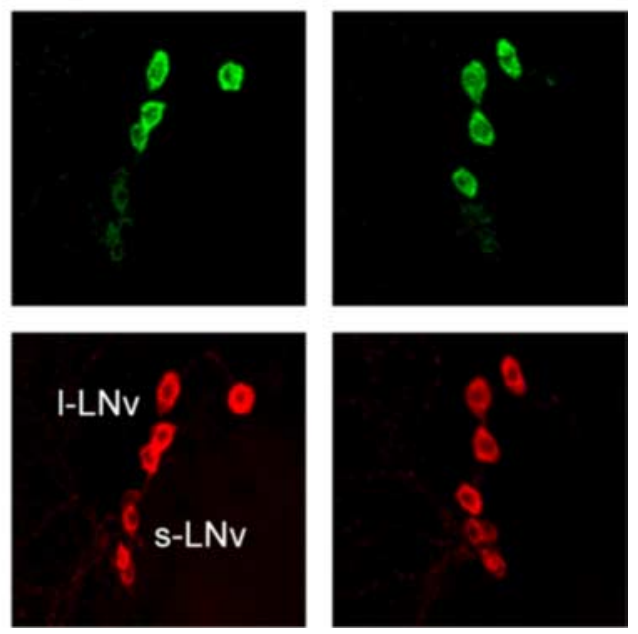
ZT10
Figure 3. Pdf-Gal4 drives constitutive expression of S6KII in clock cells. Top and bottom show PDF (green) and S6KII (red) mutant, similar to results with wild-type flies (supplemental Fig. 1, available at www jneurosci org as supplemental material). Six brains were examined at each time point in these experiments, with similar results. See Materials and Methods for details about immunostaining procedures.

\section{Rhythmic changes in S6KII abundance are not required for normal circadian behavior}

Although we could not detect S6KII in wild-type fly brains (see above), using an existing antibody (Kim et al., 2006), we wondered whether it might be possible to detect the protein in flies overexpressing the protein. Thus, we performed immunostaining experiments using the anti-S6KII antibody and brains from adult $p d f$-Gal4; UAS-S6KII flies. As shown in Figure 3, pdf-Gal4driven overexpression permitted detection of S6KII within the large and small PDF-containing LNv neurons. In these conditions, the protein had a predominantly cytoplasmic localization, as seen by comparison of the S6KII signal (red) to that for PDF (green). Moreover, there was a constitutively high, nonoscillating level of S6KII in such flies, the expected result as the $p d f$ promoter is not regulated in a circadian manner (Park and Hall, 1998). As pdf-Gal4-driven S6KII can rescue circadian period (Fig. 2, Table 1 ), this result indicates that rhythmic changes in S6KII abundance are not required for the manifestation of normal circadian behavior.

Our behavioral experiments showed that tim-Gal4- and timUAS-Gal4-driven S6KII also rescued circadian period (Fig. 2, Table 1). It is known from many published studies that the timGal4 driver expresses Gal4 activity according to a circadian rhythm that reflects the endogenous tim promoter. In contrast, it has previously been shown that tim-UAS-Gal4 drives lowamplitude ( $\sim$-fold) rhythms in Gal4 activity (Blau and Young, 1999) that are anti-phase to the normal tim rhythm and in phase with the S6KII RNA rhythm (Fig. 1). Indeed, we examined S6KII abundance in tim-UAS-Gal4; UAS-S6KII brains and detected an approximate threefold change in abundance between ZT1.5 and ZT10 within the large and small PDF-positive $\mathrm{LN}_{\mathrm{v}} \mathrm{s}$ (supplemental Fig. 1, available at www.jneurosci.org as supplemental material), similar to the expression profile documented for vrille in tim-UAS-Gal4; UAS-vrille flies (Blau and Young, 1999). Thus, tim-Gal4 and tim-UAS-Gal4 drive expression with opposite phases whereas pdf-Gal4 results in constitutive expression. The 

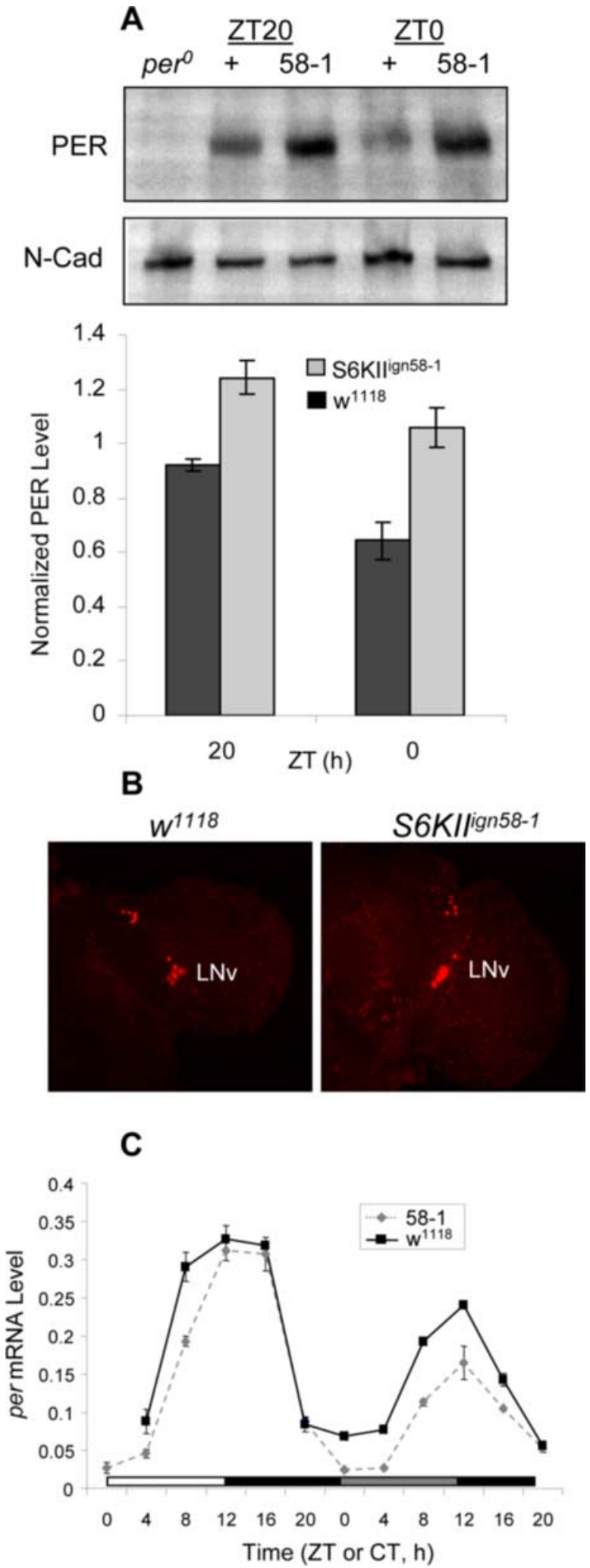

Figure 4. PER clock protein and per gene expression are altered in the $S 6 K I I^{i g n 58-1}$ mutant. $A$, PER is abnormally high in 58-1 head extracts at Zeitgeber times (ZT) 20 and 0. Blots were probed with a rabbit anti-PER antibody, stripped and then reprobed with rat anti-N-cadherin as a loading control. The blot shown is representative of three biological replicates. Histograms represent densitometric measurements minus background and normalized to $\mathrm{N}$-cadherin (mean \pm SEM). At both times of day, the mean PER signal is statistically different between the mutant and control ( $p<0.02$, Welch's $t$ test). $\boldsymbol{B}$, PER immunoreactivity is increased within the PDF-positive large and small LNv neurons and perhaps other cell types of the S6KIIIn58-1 mutant relative to controls $\left(w^{1118}\right)$. PER immunoreactive signals were blindly ranked on a scale of $1-5$, observation that pdf-Gal4, tim-Gal4 and tim-UAS-Gal4 can all rescue the circadian period phenotype of S6KII ${ }^{\text {ign58-1 }}$ demonstrates that constitutive expression, normally phased expression or anti-phase expression of S6KII are equally sufficient for normal behavioral rhythmicity. If rhythms in S6KII activity are required for normal behavior, then they might come about via rhythmic post-translational modification(s) of the protein, similar to those observed for the Drosophila CLK protein (Yu et al., 2006).

\section{S6KII ${ }^{\text {ign58-1 }}$ alters PER clock RNA and protein dynamics in vivo}

The short-period locomotor activity rhythm phenotype of S6KII ${ }^{\text {ign58-1 }}$ flies suggests that S6KII alters the circadian molecular oscillator. To assess oscillator function, we examined rhythmicity of the clock component period (per). It is known that PER is highly phosphorylated and most abundant in the late night and early morning. At such times (ZT16, ZT20, ZT0 and ZT4), S6KII ign58-1 fly head extracts had abnormally high levels of PER, relative to control flies (Fig. 4A, data not shown). Increased PER immunoreactivity, indicative of abundance, was evident in the PDF neurons and perhaps other cell types of the mutant as assessed by immunostaining (Fig. $4 B$ ), consistent with the idea that S6KII is required within pacemaker cells for normal oscillator function. Changes in PER abundance were most noticeable near the end of night (ZT20 and ZT0) when PER is nuclear and strongly represses clock gene transcription. Consistent with an effect on repression, Q-PCR analysis of per mRNA demonstrated that per mRNA level was decreased in S6KII ${ }^{\text {ign58-1 }}$ flies at most times of day in DD conditions (Fig. 4C). Whereas this effect was observed at certain times of day in LD, it was most pronounced in $\mathrm{DD}$ and seen in three independent experiments (Fig. 4C, data not shown). Increased PER protein and decreased per message levels in the $S 6 \mathrm{KII}^{\text {ign58-1 }}$ mutant indicate that the clock protein has enhanced stability, perhaps due to altered phosphorylation, and that this results in increased feedback repression.

\section{Decreased SKII is associated with increased PER feedback repression}

To determine whether decreased S6KII affected per-gene transcription, we performed gene reporter assays using cultured S2 cells expressing an E-box-luciferase reporter transgene (see Methods). We used RNAi techniques to knock down S6KII in S2 cells and monitored PER feedback repression in this system. As a control, we performed a cell-based knockdown of CK $2 \alpha$, similar to that reported by Nawathean and Rosbash (2004). We found that $\mathrm{S} 2$ cells endogenously express S6KII mRNA and that incubation of cells with S6KII-specific dsRNA reduced the level of the message to $\sim 30 \%$ of normal ( $p$ value $=0.003$; Welch's twosample, one-sided $t$ test); a similar level of RNAi knockdown was previously reported for CK2 $\alpha$ using dsRNA specific for that message (Nawathean and Rosbash, 2004). In contrast, S6KII knockdown was associated with increased PER feedback repression, as shown by a decrease in normalized luciferase activity (Fig. 5).

$\leftarrow$

with 5 being the most intense signal, and the panels shown here are representative results. The $w^{1118}$ panel shown in this figure received a score of 2, the average for this genotype, whereas the $56 K_{I I} I^{\text {ign58-1 }}$ panel was ranked a 4, the average for the mutant. Images represent a series of collapsed $1 \mu \mathrm{m}$ sections. This experiment was repeated three times with similar results. $\boldsymbol{C}$, per mRNA titers are reduced in 58-1 flies. This plot is representative of three biological replicates, each repeated in triplicate. Ct values were normalized to those of the noncycling housekeeping gene rp49. Data points are means \pm SEM of each triplicate. 


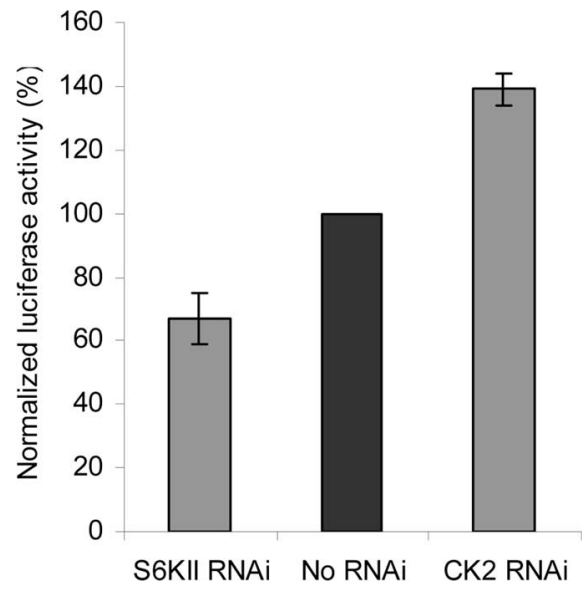

Figure 5. Decreased S6KII is associated with increased PER-mediated repression. Histogram plots showing percentage changes in luciferase activity, reflecting differences in PER feedback repression (mean $\pm \mathrm{SEM}$ ). S6KII and CK2 $\alpha$ knockdown results were normalized by plotting each as a percentage of the no RNAi control. These results represent data from four independent experiments; in each experiment, PER repression was increased with S6KII knockdown and decreased with CK2 $\alpha$ knockdown. Normalized values of luciferase activity, expressed as the number of SDs from the mean (see Materials and Methods), were analyzed to statistically evaluate differences among the three conditions. According to that analysis, the distributions for S6KII and CK2 $\alpha$ knockdowns are significantly different from each other and from that for the No RNAi control ( $p \leq 0.002$, Welch's two-tailed $t$ test).

These data are consistent with the results described above that demonstrate reduced per mRNA levels in S6KII ${ }^{\text {ign } 58-1}$ flies. The opposite effects of CK $2 \alpha$ and S6KII knockdown in cell-based assays are correlated with behavioral results showing long- and short-period circadian activity rhythms, respectively, in the two types of mutants.

\section{S6KII physically interacts with CK2 $\beta$}

It is known that CK2 is enriched in the PDF clock cells of the adult fly brain (J. M. Lin et al., 2002; Akten et al., 2003), and required in those cells for normal behavioral rhythmicity (Smith et al., 2008) (V.Sundram and F. R. Jackson, unpublished results). In addition, an interaction between human RSK and the casein kinase 2 regulatory subunit (CK2 $\beta$ ) was previously detected in a yeast twohybrid screen (Kusk et al., 1999). We have identified an interaction between Drosophila S6KII and CK2 $\beta$ in cell-based assays performed in HEK293 cells (Fig. 6). When plasmids encoding HA-tagged CK2 $\beta$ and Myc-tagged S6KII were transfected into HEK293 cells, the two proteins could be coimmunoprecipitated using an anti-HA antibody. As a positive control, CK2 $\beta$ could also immunoprecipitate CK2 $\alpha$, the catalytic subunit of CK2 (Fig. 6). CK $2 \alpha$ phosphorylates $\mathrm{CK} 2 \beta$ at three $\mathrm{N}$-terminal serine residues, which results in an increase in molecular weight. It is interesting to note that in the presence of $\mathrm{CK} 2 \alpha, \mathrm{CK} 2 \beta$ was detected as a doublet of bands, indicating a high degree of phosphorylation. In contrast, coexpression of CK $2 \beta$ with S6KII did not result in the appearance of a slower migrating $\mathrm{CK} 2 \beta$ protein, indicating that S6KII does not phosphorylate CK2 $\beta$.

Another apparent difference between CK $2 \alpha$ and S6KII is the mode of interaction with CK2 $\beta$. Assembly of the heterotetrameric CK2 $\left(\alpha_{2} \beta_{2}\right)$ holoenzyme requires dimer formation between two CK2 $\beta$ molecules, which is mediated by a zinc finger structure (Chantalat et al., 1999; Niefind et al., 2001). A mutant form of $\mathrm{CK} 2 \beta$, in which two cysteine residues within the zinc finger structure were changed to serine residues $\left(\mathrm{CK} 2 \beta^{\mathrm{C} 109,114 \mathrm{~S}}\right)$, was unable to interact with CK2 $\alpha$ (Fig. 6). Consistent with a lack of phosphorylation in the absence of $\mathrm{CK} 2 \alpha$, the $\mathrm{CK} 2 \beta$ was present only as a single band. Interestingly, S6KII could be precipitated by the dimerization defective $\mathrm{CK} 2 \beta^{\mathrm{C} 109,114 \mathrm{~S}}$ protein (Fig. 6).

\section{The S6KII ${ }^{\text {ign } 58-1}$ allele genetically interacts with CK2 mutations}

Based on the observation that S6KII and CK $2 \beta$ can physically interact, we sought genetic evidence for an interaction in vivo. Thus, we analyzed behavioral rhythms in double mutants carrying Andante and S6KII ${ }^{\text {ign58-1 }}$; Andante behaves similar to a hypomorphic allele of the essential CK2 $\beta$ gene whereas $S 6 K_{I I}{ }^{i g n 58-1}$ is a null allele of S6KII. We reasoned that genetic epistasis might be observed if CK2 $\beta$ and S6KII cooperate in vivo. Alternatively, if the two proteins function in different pathways, then the double mutant is expected to have an intermediate phenotype; i.e., a near wild-type circadian period). As shown in Table 1, double mutants had long-period rhythms, similar to Andante, and this result indicates that CK2 $\beta$ and S6KII interact in vivo. Similarly, S6KII ign58-1 ; Tik (a CK2 $\alpha$ allele; (J. M. Lin et al., 2002) had longperiod rhythms although they were slightly shorter than those of Tik single mutants (Table 1). These results are consistent with the idea that S6KII function requires normal CK2 activity.

\section{Discussion}

A role for S6KII in the molecular oscillator

We have shown that a null mutant for Drosophila S6KII $\left(S 6 K I^{i g n 58-1}\right)$ exhibits a short-period locomotor activity rhythm, indicating a requirement for the kinase in the molecular oscillator. Consistent with such a role, S6KII mRNA shows circadian oscillations in abundance. Although we cannot detect rhythms in S6KII protein abundance or activation (by phosphorylation) within clock neurons using currently available reagents, these remain possibilities as a mechanism for producing rhythms in kinase activity. Alternatively, constitutive expression of S6KII may be sufficient for normal behavior, similar to the case for other circadian kinases. To our knowledge, S6KII represents the first nonessential kinase or phosphatase with a posttranscriptional role in regulating the circadian molecular oscillator. Null mutants of $D b t$ (CKI $\varepsilon$ ), $S g g$ (GSK-3 $\beta$ ), PP2A, or CK2 $\alpha$ / $C K 2 \beta$ arrest in development during embryonic or larval stages (Bourouis et al., 1989; Jursnich et al., 1990; Jauch et al., 2002; Sathyanarayanan et al., 2004).

\section{S6KII and CK2 cooperate, in vivo, to determine circadian period}

We have shown that S6KII can physically interact with the CK2 $\beta$ subunit in cultured cells and that there are genetic interactions between mutations affecting the two kinases in vivo. This study provides the first evidence for an interaction between kinases, in vivo, that regulates circadian period. Both CK2 and S6KII are required within clock cells for normal circadian period, consistent with a model wherein they cooperate to regulate molecular oscillator function. Previous studies have suggested a functional interaction between CK2 and the Dbt (CK1 $\varepsilon$ ) kinase, using cellbased assays with the two kinases (Nawathean and Rosbash, 2004), but there is no evidence supporting such an interaction in vivo. Although we do not know the targets that are relevant for S6KII function, a likely possibility is regulation of PER phosphorylation via the CK2 kinase (Lin et al., 2005), based on the interaction between S6KII and CK2. As S6KII and CK2 mutants have opposite circadian period phenotypes, S6KII binding may inhibit CK2 activity to modulate the PER-mediated repression of clock 


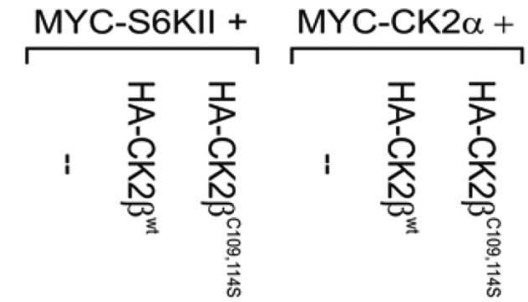

lysate MYC-S6KII

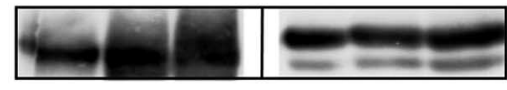

\section{lysate MYC-CK2 $\alpha$}

\begin{abstract}
IP: anti-HA
WB: S6KII

IP: anti-HA

WB: $\quad$ CK2 $\beta$
\end{abstract}

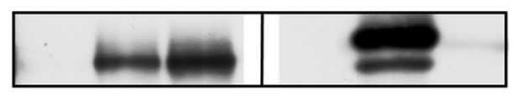

IP: anti-HA
WB: $\quad$ CK $2 \alpha$

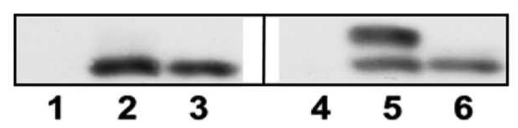

IP: anti-HA

WB: $\quad$ CK2 $\beta$

Figure 6. Interaction of S6KII with CK2 $\beta$. MYC-S6KII or MYC-CK2 $\alpha$ were either individually transfected in HEK293 cells (lanes

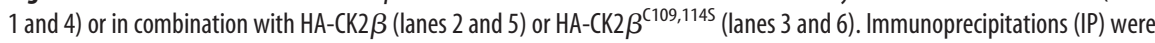
done with an anti-HA antibody and purified protein complexes were analyzed by Western blot (WB) with anti-HA and anti-Myc antibodies. Expression of MYC-S6KII and MYC-CK2 $\alpha$ in all samples was confirmed by Western blot analysis of total cell lysates.

gene transcription. Consistent with such a downstream and opposing role, CK2 overexpression in the fly eye suppresses a S6KIIgenerated overexpression phenotype (MMT, BA and FRJ unpublished results).

Regarding a role for S6KII in modulating PER phosphorylation, we point out that our results are entirely consistent with previous studies that postulate a role for CK2 in regulating PERmediated repression (Nawathean and Rosbash, 2004; Smith et al., 2008). Cell-based per-reporter studies performed by Nawathean and Rosbash (2004) showed that knockdown of CK2 resulted in decreased PER repressor activity, and we have replicated these findings on CK2 in our analysis of S6KII. Our results show that knockdown of S6KII in such cell-based reporter assays is associated with increased PER-mediated repression, consistent with the hypothesis that wild-type S6KII inhibits CK2 activity. The analysis of per RNA in the S6KII mutant shows a reduced abundance, consistent with increased PER repression. Smith et al. (2008) have recently shown that overexpression of a CK2 $\alpha$ dominantnegative mutant subunit $\left(\mathrm{CK} 2 \alpha^{\text {tik }}\right)$ causes increased per RNA abundance that is associated with constitutively high PER, a delayed nuclear entry for the clock protein and long-period rhythmicity, effects that are consistent with decreased PER repression. per mRNA abundance is also abnormally high in a mutant ( $A n$ dante) of the CK $2 \beta$ subunit (B. Akten and F. R. Jackson, unpublished results), consistent with decreased repression. The aggregate of all these results strongly supports a role for CK2 in modulating PER-mediated repression and an inhibitory function for S6KII in this process. Although our results indicate that S6KII may act through CK2 to regulate PER phosphorylation, it is also possible that the two kinases intersect on a common target (PER?) with CK2 phosphorylation of the target being required for S6KII biochemical action.

\section{S6KII phosphorylation status and clock function}

RSK1, the mammalian S6KII homolog, is phosphorylated in a clock-dependent manner (Butcher et al., 2004). Although we have not been able to detect rhythmic phosphorylation of S6KII with available reagents, this remains a formal possibility as there are many known RSK1 sites of phosphorylation, including those for PDK1 and ERK/MAPK, conserved in the fly S6KII sequence.
We lack reagents to determine whether the phosphorylation status and nuclear entry of fly S6KII is gated in a light-dependent manner, similar to its mammalian counterpart, but there is no evidence from an analysis of an S6KII mutant for an alteration of light-dependent clock resetting behavior. Based on the results reported here, we think that the primary function of fly S6KII is to regulate the period of the circadian oscillator via interaction with CK2 and modulation of PER phosphorylation (Lin et al., 2005; Smith et al., 2008).

It is known that mammalian RSK1 can be phosphorylated in a MAPK-dependent manner. Although we have not yet looked for interactions between the S6KII and MAPK pathways, it has recently been reported that Drosophila S6KII functions in the MAPK pathway to determine photoreceptor development (Kim et al., 2006). In addition, a previous study (Williams et al., 2001) concluded that MAPK signaling represents a component of the circadian output pathway regulating locomotor activity. Moreover, studies of the mammalian SCN have shown that MAPK activity is important for resetting and/or for robust cycling of the molecular oscillator (Obrietan et al., 1998; Akashi and Nishida, 2000; Coogan and Piggins, 2003; Akashi et al., 2008). Thus, it will be of interest to determine the connection between the MAPK pathway and S6KII in clock function.

\section{A model for S6KII function in the molecular oscillator}

Figure 7 shows our working model for a S6KII-CK2 feedback loop which we postulate modulates circadian period. As illustrated in this model, there is clock regulation of S6KII mRNA levels. Given the S6KII RNA cycle, we think it is likely that there is rhythmic S6KII protein production, and/or perhaps rhythmic activation of the kinase, in certain neurons although constitutive S6KII abundance is sufficient for normal behavior. Based on physical and genetic interactions, we hypothesize that S6KII negatively regulates CK2 action, and that this may result in oscillations of CK2 activity within clock neurons; at present, it is impossible to specify the phasing of such a rhythm without knowing more about the regulation of S6KII activity. Our results indicate that changes in S6KII amount might regulate PER phosphorylation via CK2. In support of an effect on PER, we have shown that peak PER protein level is abnormally high in the $S 6 \mathrm{KII}^{\text {ign58-1 }} \mathrm{mu}$ tant at certain times of day and that per RNA titer is decreased, in particular in DD conditions. Abnormally high levels of nuclear phospho-PER in the S6KII mutant together with decreased per mRNA levels are consistent with the idea that a post-translational modification of PER results in enhanced per-gene repression. Our results from the use of cell-based assays support the idea that decreased S6KII results in increased PER-based repression. As a consequence, the repression phase of the molecular cycle may be abbreviated resulting in a short-period molecular oscillator. Of note, results from another recent study indicate that increased per transcription, rather than increased repression, can also shorten the period of the fly molecular oscillator (Kadener et al., 2008), consistent with the idea that altering either the transcription or repression phases can shorten circadian period.

It is of interest to compare our hypothesis for the action of 


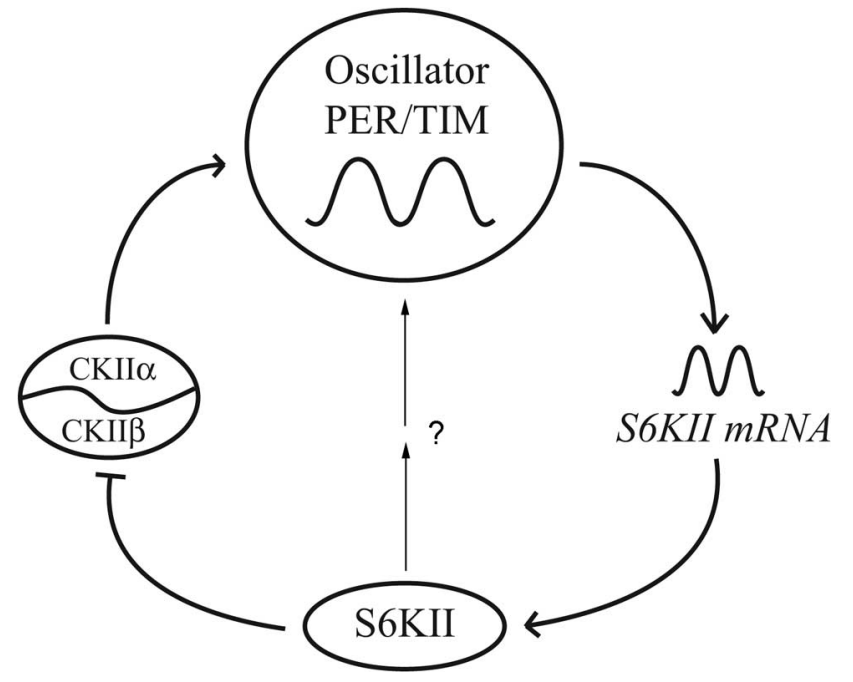

Figure 7. Hypothetical model for an S6KII/CK2 feedback loop. S6KII transcription and presumably S6KII protein abundance are regulated in a circadian manner. We hypothesize that binding of $S 6 \mathrm{KII}$ to CK2 $\beta$ inhibits CK2 activity thus altering PER phosphorylation and molecular oscillator function. As S6KIII is known to have other targets, it is also possible that the kinase regulates oscillator function through another pathway (indicated in the model by the arrows and question mark).

S6KII, in the control of PER activity, to that recently elaborated for the fly Dbt kinase (Kivimae et al., 2008). The studies of Kivimae et al. show that Dbt phosphorylation of two distinct sites within PER inversely affect stability and repressor activity of the clock protein. For example, Dbt phosphorylation of PER in the "per-short" region stabilizes the protein while decreasing its potency as a repressor. In contrast, our results suggest that a deficit for S6KII, and presumably altered CK2 activity, produces a PER protein with increased stability and normal or enhanced repressor activity. Notably, Dbt and CK2 phosphorylation sites have been mapped to within short overlapping $\mathrm{N}$-terminal regions of PER (Lin et al., 2005; Kivimae et al., 2008) and it is possible that there is interaction between the kinases in modifying the clock protein. The precise role of S6KII in regulating CK2 or another component of the molecular oscillator will only be revealed through detailed biochemical analysis of its function.

\section{References}

Akashi M, Nishida E (2000) Involvement of the MAP kinase cascade in resetting of the mammalian circadian clock. Genes Dev 14:645-649.

Akashi M, Hayasaka N, Yamazaki S, Node K (2008) Mitogen-activated protein kinase is a functional component of the autonomous circadian system in the suprachiasmatic nucleus. J Neurosci 28:4619-4623.

Akten B, Jauch E, Genova GK, Kim EY, Edery I, Raabe T, Jackson FR (2003) A role for CK2 in the Drosophila circadian oscillator. Nat Neurosci 6:251-257.

Benito J, Zheng H, Hardin PE (2007) PDP1 epsilon functions downstream of the circadian oscillator to mediate behavioral rhythms. J Neurosci 27:2539-2547.

Blau J, Young MW (1999) Cycling vrille expression is required for a functional Drosophila clock. Cell 99:661-671.

Bourouis M, Heitzler P, el Messal M, Simpson P (1989) Mutant Drosophila embryos in which all cells adopt a neural fate. Nature 341:442-444.

Butcher GQ, Lee B, Hsieh F, Obrietan K (2004) Light- and clock-dependent regulation of ribosomal $\mathrm{S6}$ kinase activity in the suprachiasmatic nucleus. Eur J Neurosci 19:907-915.

Ceriani MF, Hogenesch JB, Yanovsky M, Panda S, Straume M, Kay SA (2002) Genome-wide expression analysis in Drosophila reveals genes controlling circadian behavior. J Neurosci 22:9305-9319.

Chantalat L, Leroy D, Filhol O, Nueda A, Benitez MJ, Chambaz EM, Cochet C, Dideberg O (1999) Crystal structure of the human protein kinase
CK2 regulatory subunit reveals its zinc finger-mediated dimerization. EMBO J 18:2930-2940.

Chintapalli VR, Wang J, Dow JA (2007) Using FlyAtlas to identify better Drosophila melanogaster models of human disease. Nat Genet 39:715-720.

Claridge-Chang A, Wijnen H, Naef F, Boothroyd C, Rajewsky N, Young MW (2001) Circadian regulation of gene expression systems in the Drosophila head. Neuron 32:657-671.

Coogan AN, Piggins HD (2003) Circadian and photic regulation of phosphorylation of ERK1/2 and Elk-1 in the suprachiasmatic nuclei of the Syrian hamster. J Neurosci 23:3085-3093.

Cyran SA, Buchsbaum AM, Reddy KL, Lin MC, Glossop NR, Hardin PE, Young MW, Storti RV, Blau J (2003) vrille, Pdp1, and dClock form a second feedback loop in the Drosophila circadian clock. Cell 112:329-341.

Dunlap JC, Loros JJ (2005) Analysis of circadian rhythms in Neurospora: overview of assays and genetic and molecular biological manipulation. J Circadian Rhythms 393:3-22.

Fang Y, Sathyanarayanan S, Sehgal A (2007) Post-translational regulation of the Drosophila circadian clock requires protein phosphatase 1 (PP1). Genes Dev 21:1506-1518.

Glossop NR, Lyons LC, Hardin PE (1999) Interlocked feedback loops within the Drosophila circadian oscillator. Science 286:766-768.

Glossop NR, Houl JH, Zheng H, Ng FS, Dudek SM, Hardin PE (2003) VRILLE feeds back to control circadian transcription of Clock in the Drosophila circadian oscillator. Neuron 37:249-261.

Grima B, Lamouroux A, Chélot E, Papin C, Limbourg-Bouchon B, Rouyer F (2002) The F-box protein Slimb controls the levels of clock proteins Period and Timeless. Nature 420:178-182.

Hardin PE (2005) The circadian timekeeping system of Drosophila. Curr Biol 15:R714-R722.

Harms E, Kivimäe S, Young MW, Saez L (2004) Posttranscriptional and posttranslational regulation of clock genes. J Biol Rhythms 19:361-373.

Jauch E, Melzig J, Brkulj M, Raabe T (2002) In vivo functional analysis of Drosophila protein kinase casein kinase 2 (CK2) beta-subunit. Gene 298:29-39.

Jauch E, Wecklein H, Stark F, Jauch M, Raabe T (2006) The Drosophila melanogaster DmCK2 beta transcription unit encodes for functionally non-redundant protein isoforms. Gene 374:142-152.

Jursnich VA, Fraser SE, Held LI Jr, Ryerse J, Bryant PJ (1990) Defective gap-junctional communication associated with imaginal disc overgrowth and degeneration caused by mutations of the dco gene in Drosophila. Dev Biol 140:413-429.

Kadener S, Stoleru D, McDonald M, Nawathean P, Rosbash M (2007) Clockwork Orange is a transcriptional repressor and a new Drosophila circadian pacemaker component. Genes Dev 21:1675-1686.

Kadener S, Menet JS, Schoer R, Rosbash M (2008) Circadian transcription contributes to core period determination in Drosophila. PLoS Biol 6:e119.

Kim M, Lee JH, Koh H, Lee SY, Jang C, Chung CJ, Sung JH, Blenis J, Chung J (2006) Inhibition of ERK-MAP kinase signaling by RSK during Drosophila development. EMBO J 25:3056-3067.

Kivimäe S, Saez L, Young MW (2008) Activating PER repressor through a DBT-directed phosphorylation switch. PLoS Biol 6:e183.

Kloss B, Price JL, Saez L, Blau J, Rothenfluh A, Wesley CS, Young MW (1998) The Drosophila clock gene double-time encodes a protein closely related to human casein kinase Ie. Cell 94:97-107.

Ko HW, Jiang J, Edery I (2002) Role for Slimb in the degradation of Drosophila Period protein phosphorylated by Doubletime. Nature 420:673-678.

Konopka RJ, Pittendrigh C, Orr D (1989) Reciprocal behaviour associated with altered homeostasis and photosensitivity of Drosophila clock mutants. J Neurogenet 6:1-10.

Kusk M, Ahmed R, Thomsen B, Bendixen C, Issinger OG, Boldyreff B (1999) Interactions of protein kinase CK2beta subunit within the holoenzyme and with other proteins. Mol Cell Biochem 191:51-58.

Lee C, Etchegaray JP, Cagampang FR, Loudon AS, Reppert SM (2001) Posttranslational mechanisms regulate the mammalian circadian clock. Cell 107:855-867.

Levine JD, Funes P, Dowse HB, Hall JC (2002) Signal analysis of behavioral and molecular cycles. BMC Neurosci 3:1.

Lim C, Chung BY, Pitman JL, McGill JJ, Pradhan S, Lee J, Keegan KP, Choe J, Allada R (2007) Clockwork orange encodes a transcriptional repressor 
important for circadian-clock amplitude in Drosophila. Curr Biol 17:1082-1089.

Lin JM, Kilman VL, Keegan K, Paddock B, Emery-Le M, Rosbash M, Allada R (2002) A role for casein kinase 2 alpha in the Drosophila circadian clock. Nature 420:816-820.

Lin JM, Schroeder A, Allada R (2005) In vivo circadian function of casein kinase 2 phosphorylation sites in Drosophila PERIOD. J Neurosci 25:11175-11183.

Lin SC, Lin MH, Horváth P, Reddy KL, Storti RV (1997) PDP1, a novel Drosophila PAR domain bZIP transcription factor expressed in developing mesoderm, endoderm and ectoderm, is a transcriptional regulator of somatic muscle genes. Development 124:4685-4696.

Lin Y, Han M, Shimada B, Wang L, Gibler TM, Amarakone A, Awad TA, Stormo GD, Van Gelder RN, Taghert PH (2002) Influence of the period-dependent circadian clock on diurnal, circadian, and aperiodic gene expression in Drosophila melanogaster. Proc Natl Acad Sci U S A 99:9562-9567.

Martinek S, Inonog S, Manoukian AS, Young MW (2001) A role for the segment polarity gene shaggy/GSK-3 in the Drosophila circadian clock. Cell 105:769-779.

Matsumoto A, Ukai-Tadenuma M, Yamada RG, Houl J, Uno KD, Kasukawa T, Dauwalder B, Itoh TQ, Takahashi K, Ueda R, Hardin PE, Tanimura T, Ueda HR (2007) A functional genomics strategy reveals clockwork orange as a transcriptional regulator in the Drosophila circadian clock. Genes Dev 21:1687-1700.

McDonald MJ, Rosbash M (2001) Microarray analysis and organization of circadian gene expression in Drosophila. Cell 107:567-578.

Meng QJ, Logunova L, Maywood ES, Gallego M, Lebiecki J, Brown TM, Sládek M, Semikhodskii AS, Glossop NR, Piggins HD, Chesham JE, Bechtold DA, Yoo SH, Takahashi JS, Virshup DM, Boot-Handford RP, Hastings MH, Loudon AS (2008) Setting clock speed in mammals: the CK1 epsilon tau mutation in mice accelerates circadian pacemakers by selectively destabilizing PERIOD proteins. Neuron 58:78-88.

Nawathean P, Rosbash M (2004) The doubletime and CKII kinases collaborate to potentiate Drosophila PER transcriptional repressor activity. Mol Cell 13:213-223.

Niefind K, Guerra B, Ermakowa I, Issinger OG (2001) Crystal structure of human protein kinase CK2: insights into basic properties of the CK2 holoenzyme. EMBO J 20:5320-5331.

Obrietan K, Impey S, Storm DR (1998) Light and circadian rhythmicity regulate MAP kinase activation in the suprachiasmatic nuclei. Nat Neurosci 1:693-700.

Park JH, Hall JC (1998) Isolation and chronobiological analysis of a neu- ropeptide pigment-dispersing factor gene in Drosophila melanogaster J Biol Rhythms 13:219-228.

Price JL, Blau J, Rothenfluh A, Abodeely M, Kloss B, Young MW (1998) Double-time is a novel Drosophila clock gene that regulates PERIOD protein accumulation. Cell 94:83-95.

Putz G, Bertolucci F, Raabe T, Zars T, Heisenberg M (2004) The S6KII (rsk) gene of Drosophila melanogaster differentially affects an operant and a classical learning task. J Neurosci 24:9745-9751.

Reppert SM, Weaver DR (2002) Coordination of circadian timing in mammals. Nature 418:935-941.

Richier B, Michard-Vanhée C, Lamouroux A, Papin C, Rouyer F (2008) The clockwork orange Drosophila protein functions as both an activator and a repressor of clock gene expression. J Biol Rhythms 23:103-116.

Rintelen F, Stocker H, Thomas G, Hafen E (2001) PDK1 regulates growth through Akt and S6K in Drosophila. Proc Natl Acad Sci U S A 98:15020-15025.

Sathyanarayanan S, Zheng X, Xiao R, Sehgal A (2004) Posttranslational regulation of Drosophila PERIOD protein by protein phosphatase 2A. Cell 116:603-615.

Smith EM, Lin JM, Meissner RA, Allada R (2008) Dominant-negative CK2 alpha induces potent effects on circadian rhythmicity. PLoS Genet 4:e12.

Stanewsky R, Jamison CF, Plautz JD, Kay SA, Hall JC (1997) Multiple circadian-regulated elements contribute to cycling period gene expression in Drosophila. EMBO J 16:5006-5018.

Suh J, Jackson FR (2007) Drosophila ebony activity is required in glia for the circadian regulation of locomotor activity. Neuron 55:435-447.

Tomita J, Nakajima M, Kondo T, Iwasaki H (2005) No transcriptiontranslation feedback in circadian rhythm of KaiC phosphorylation. Science 307:251-254.

Ueda HR, Matsumoto A, Kawamura M, Iino M, Tanimura T, Hashimoto S (2002) Genome-wide transcriptional orchestration of circadian rhythms in Drosophila. J Biol Chem 277:14048-14052.

Williams JA, Su HS, Bernards A, Field J, Sehgal A (2001) A circadian output in Drosophila mediated by neurofibromatosis-1 and Ras/MAPK. Science 293:2251-2256.

Young MW, Kay SA (2001) Time zones: a comparative genetics of circadian clocks. Nat Rev Genet 2:702-715.

Yu W, Zheng H, Houl JH, Dauwalder B, Hardin PE (2006) PER-dependent rhytms in CLK phosphorylation and E-box binding regulate circadian transcription. Genes Dev 20:723-733.

Zheng X, Sehgal A (2008) Probing the relative importance of molecular oscillations in the circadian clock. Genetics 178:1147-1155. 